3 Nakamura Y, Oki I, Tanihara S, Ojima T, Yanagawa H. Cardiac sequelae in recurrent cases of Kawasaki disease: a diac sequelae in recurrent cases of Kawasaki disease: a comparison between the initial episode of the disease and
recurrence in the same patients. Pediatrics 1998;102:E66.

4 King J, Schlieper A, Birdi N, Capelli M, Korneluk Y, Rowe P. Kawasaki syndrome and its effects on cognitive, academic and behavioural function. A case control study. Pediatr Res 1996;39:18A.

5 Sundel RP, Newburger JW, McGill T, et al. Sensorineura hearing loss associated with Kawasaki disease. I Pediat 1990;117:371-7.
6 Michie CA, Tulloh R, Mills G, Davidson S. Kawasaki syndrome may be associated with behavioural and learning syndrome may be associated with behav

7 Manders SM, Heymann WR, Atillasoy E, Kleeman J, Schlievert PM. Recurrent toxin-mediated perineal erythema. Arch Dermatol 1996;132:57-60.

8 Viard I, Wehrli P, Bullani R, et al. Inhibition of toxic epidermal necrolysis by blockade of CD95 with human intravenous immunoglobulin. Science 1998;281:490-3.

9 Michie CA, Cohen J. Clinical significance of superantigens. Trends Microbiol 1998;6:61-5.

\title{
EUROPE CALLING
}

\section{Coincidence is not causality - a principle which needs regular rediscovery}

After the long debates on the safety of pertussis whole cell vaccines had finally been settled (they had been accused of causing severe brain damage in a subset of vaccinated infants and young children), new trouble recently arose with reports on the perceived side effects of immunisation. ${ }^{2-4}$

It was not enough that for almost two decades hundreds of thousands of children had to suffer unnecessarily from whooping cough and its complications after scares among lay persons and professionals fuelled by case reports and reports in the media on serious post immunisation illnesses. This led to under or non-use of the vaccine in many European countries, primarily Germany, Italy, and Sweden. The simple principle that "coincidence is no proof of causality" has been again neglected and new fears have been raised by studies that have inappropriate conclusions-for example, colitis and pervasive developmental disorders (autism), diabetes mellitus with onset at early age, and demyelinating diseases have been attributed to measles, mumps, and rubella (MMR) immunisation in the $\mathrm{UK},{ }^{4}$ invasive Haemophilus influenzae type B (Hib) diseases in Finland, ${ }^{35}$ and hepatitis B in France. ${ }^{2}$

The consequences were far reaching and have led to the decline of MMR immunisation rates in the UK and suspension of routine school-based vaccination of adolescents against hepatitis B in France, even though scientific evidence was against the allegations. ${ }^{67}$ The Hib/diabetes issue, fortunately, has not had any recognisable effect on Hib vaccine coverage in Finalnd or any other European country.

The reasons for the general public's enormous and, it seems, ever increasing interest in vaccine damage are multifactorial and rather easy to understand: an effective programme of vaccination leads to a reduced rate of occurences of the disease it seeks to prevent. Thus, the public fear of a serious illness - for example, poliomyelitis, becomes theoretical in the lack of actual cases, and the acceptance of an immunisation programme decreases. In parallel, public interest increasingly focuses on the perceived (or real) side effects of the vaccine. This is the dilemma we have to fight against.
Ideally, all parties concerned with vaccine safety-that is, the patients or their parents, legal authorities, manufacturers, and immunising physicians, should have a common interest in discriminating between coincidence and causal link of post-immunisation adverse events in order to maintain confidence in our successful vaccination programmes. Unfortunately, this is hardly ever the case. On 23 May 2000, despite overwhelming evidence that there is no causal link between multiple sclerosis and other demyelinating diseases and hepatitis $\mathrm{B}$ immunisation, ${ }^{7}$ the French Ministry of Health announced that it had decided to give financial compensation to eight individuals who had claimed serious medical problems after hepatitis B immunisation. The Ministry of Health argued that there is a causal link between hepatitis B immunisation and serious medical problems-French journalists picked up on this and spread the news that "new data" indicated a causal link (CA Siegrist, personal communication). There is no such new data and I wonder what the next story will be. (By the way, I observed side effects in both my daughter and my son within two weeks of their first dose of MMR at the age of 12 months: they both said "Daddy" for the first time shortly afterwards and also soon started to walk.)

ULRICH HEININGER European Associate Editor

1 Cherry JD. Pertussis vaccine encephalopathy: it is time to recognize it as the myth that it is. $¥ A M A 1990 ; 263: 1679-80$.

2 Herroelen L, de Keyser J, Ebinger G. Central nervous system demyelination after immunisation with recombinant hepatitis B vaccine. Lancet 1991;338: after imm

3 Classen JB, Classen DC, White H. Association between type 1 diabetes and Hib vaccine. BM7 1999;319:1133.

4 Wakefield AJ, Murch SH, Anthony A, et al. Ileal-lymphoid-nodular hyperplasia, non-specific colitis, and pervasive developmental disorder in children. Lancet 1998;351:637-41

5 Karvonen M, Cepaitis Z, Tuomilehto J. Association between type 1 diabetes and Haemophilus influenzae type $\mathrm{b}$ vaccination: birth cohort study. $B M \mathcal{F}$ 1999;318:1169-72

6 Taylor B, Miller E, Farrington CP, et al. Autism and measles, mumps, and rubella vaccine: no epidemiological evidence for a causal association. Lancet 1999;353:2026-9.

7 Hall A, Kane M, Roure C, Meheus A. Multiple sclerosis and hepatitis B vaccine? Vaccine 1999;17:2473-5. 